\title{
EFFECT OF VASOACTIVE DRUGS ON GASTRIC BLOOD FLOW MEASURED BY A CROSS THERMOCOUPLE METHOD IN RATS
}

\author{
Shingo YANO, Eiichi HOSHINO and Masatoshi HARADA \\ Department of Drug Evaluation and Toxicological Sciences. Faculty of Pharmaceutical Sciences, \\ Chiba University, 1-33, Yayoi. Chiba 260, Japan
}

Accepted September 13, 1980

\begin{abstract}
To make a continuous recording of gastric blood flow (GBF) in rats, application of a cross thermocouple method was investigated together with related pharmacological studies. When secretagogues (tetragastrin. histamine and methacholine) were given intravenously in a dose sufficient to stimulate acid secretion, the increases in GBF observed were much the same as those seen when the aminopyrine clearance technique was used. When epinephrine and norepinephrine were administered via a close intraarterial route in the stomach, there was an initial decrease followed by an increase in the GBF. This biphasic response was antagonized by phentolamine, but not by propranolol, thereby suggesting that those agonists predominantly stimulate $\alpha$-adrenoceptors. On the contrary, isoprenaline produced an increase in GBF which was attenuated by propranolol. Acetylcholine produced an increase in GBF, which was blocked by atropine. Histamine increased the GBF, and such was inhibited by diphenhydramine, but not by cimetidine, suggesting a stimulation of $\mathrm{H}-1$ receptors by histamine. Serotonin, in a lower dose, and tetragastrin also elicited an increase in GBF. However, with a higher dose of serotonin, there was an increase followed by an apparent decrease in GBF. From these results, it was concluded that the cross thermocouple method is practical for a continuous recording the rat $\mathrm{GBF}$ in response to vasoactive drugs.
\end{abstract}

Gastric blood flow is closely associated with gastric physiological functions or pathophysiological changes of gastric mucosa subjected to ulcerogenic conditions (1-4). With respect to methods for continuously measuring gastric blood flow, however. few methods provide such estimations of gastric blood flow in small animals such as rats $(5,6)$ which are widely used for pharmacological studies. A cross thermocouple method is a simple, practical one that enables a continuous monitoring of tissue blood flow on the basis of heat clearance (7), and has so far been applied to many tissues (8).
However, if thin or small tissues have to be used for study, there is a considerable difficulty in implanting a thermocouple element in the exact position and the responses are thus less pronounced.

The present work was an attempt to demonstrate that the cross thermocouple method is applicable to the rat gastric mucosa and can be compared to findings with the aminopyrine clearance technique. Using the cross thermocouple method, the effect of various vasoactive drugs on gastric tissue blood flow (GTBF) was studied regarding features of microcirculation in the 
rat stomach.

\section{MATERIALS AND METHODS}

Male Wistar rats weighing 300 to $330 \mathrm{~g}$ were deprived of food $16 \mathrm{hr}$ before each experiment but water was allowed ad libitum. After anesthesia with urethane $(2 \mathrm{~g} / \mathrm{kg}, \mathrm{i} . \mathrm{p}$.$) .$ the trachea was cannulated and a midline laparotomy done to expose the stomach. Polvethylene tubings were inserted to three positions; the right carotid artery for blood sampling and/or measurement of blood pressure, the left femoral vein for an i.v. administration of drugs, and the splenic artery, retrogradely, for a close intra-arterial (i.a.) injection of drugs to the stomach (Fig. 1).

Cross thermocouple method: A wire-typed cross thermocouple element ( $W-41$. Unique Medical) was transversally implanted, using a sewing needle, into the gastric wall of the glandular portion with a serosal access (Fig. 1). In this way, the thermocouple elements were microscopically demonstrated to be located mostly within the mucosal layer.

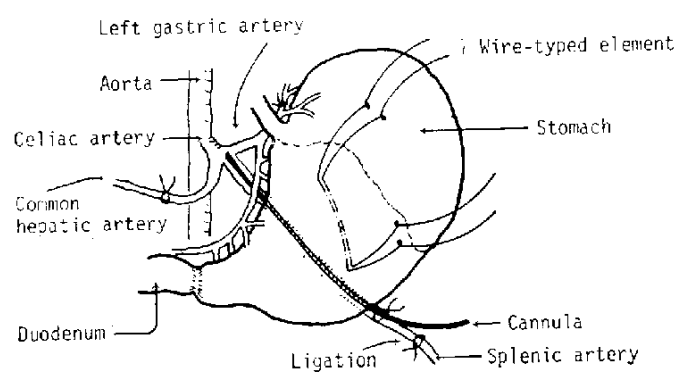

Fig. 1. Implantation of a cross thermocouple element into gastric wall and cannulation for a close i.a. administration. A wire-typed element was transversally implanted from the lesser curvature to the greater curvature. A cannula for a close i.a. injection of drugs was retrogradely inserted into the splenic artery and the tip of the cannula was positioned at the parting of the left gastric artery. The associated branch vessels and the common hepatic artery were ligated so that a solution could drain into the left gastric artery.
Electric potential, which was theoretically considered to correlate with tissue blood flow on the basis of heat clearance (7), was monitored on a recorder (056. Hitachi) via an amplifier (UM 2000. Unique Medical). Changes of GTBF by gastric secretagogues and by antagonists to vasoactive agents were expressed as a potential change $(\mu V)$ from the potential levels in the basal state and as a percentage (\%) of the potential levels of those control responses, respectively.

Aminopyrine clearance method: Measurement of gastric mucosal blood flow (GMBF) using aminopyrine clearance was made by the method of Jacobson et al. (9) on the basis of the principle described by Shore et al. (10). After a loading dose $(20 \mathrm{mg} / \mathrm{kg})$ of aminopyrine had been infused through the femoral vein over a period of $10 \mathrm{~min}$, a maintenance dose $(5 \mathrm{mg} / \mathrm{kg} / \mathrm{hr})$ was continuously infused using a perfusion pump (KN-201 D. Natsume). The stomach was washed several times with saline $10.9 \%$ $\mathrm{NaCl}$ solution) through an opening made in the forestomach. A rubber catheter for perfusing acidic saline ( $\mathrm{pH} 3.0$ ) was transorally introduced into the stomach, and the tip was placed below the cardia. Another polyvinyl catheter for sampling gastric perfusates was also inserted into the pyloric portion through the opening in the forestomach. After pyloric ligation, perfusion of the acidic saline was started at a rate of $0.5 \mathrm{ml} / \mathrm{min}$ using a perfusion pump (TMP-15 E. Toyo-Kagaku-Sangyo). Gastric perfusates were collected every $30 \mathrm{~min}$. their acid concentrations were titrated with $0.02 \mathrm{~N}$ $\mathrm{NaOH}$ using a $\mathrm{pH}$ stat (RAT-11S, HiranumaSangyo), and the concentrated perfusates, as well as blood samples, were used for the determination of aminopyrine concentrations. Blood samples were collected at the end of each experiment, as our preliminary studies demonstrated that aminopyrine blood concentrations of each rat were fairly constant 
during a period of $5 \mathrm{hr}$ from the 1 st to the 6 th hour after aminopyrine infusion.

Drugs: Drugs used were acetylcholine chloride (Daiichi), DL-norepinephrine hydrochloride, L-epinephrine hydrochloride (Sankyo), L-isoprenaline hydrochloride (Tokyo Kasei), methacholine chloride, histamine dihydrochloride, atropine sulfate, serotonin (Wako), tetragastrin (Teikokuzohki), phentolamine mesylate (CIBA), propranolol hydrochloride (Sumitomo), diphenhydramine hydrochloride (Kowa), and cimetidine (SKF). These drugs were dissolved or suspended in saline. Vasoactive agonists were given via an i.a. route. Their antagonists, when necessary, were given i.v. 5-10 $\mathrm{min}$ before the administration of agonists. Drug doses were expressed in terms of the salt.

Statistical significance was evaluated using Student's $t$-test.

\section{RESULTS}

1. Evaluation of the cross thermocouple method for determination of gastric blood flow and a comparison of the findings with use of the aminopyrine clearance technique:

Two methods for measurement of blood flow, i.e. cross thermocouple and aminopyrine clearance, were compared by simultaneously determining responses of gastric blood flow to three different secretagogues. According to the cross thermocouple method. an increase in GTBF occurred at the first 5 -min period and subsided at the second 5 -min period after administration of each secretagogue (Fig. 2). When measured by the aminopyrine clearance technique, an increase in GMBF appeared at the first 30-min period and disappeared at the next period (Fig. 3). As to responses to individual secretagogues, histamine $(300 \mu \mathrm{g} / \mathrm{kg}$, i.v.) and tetragastrin (7.5 $\mu \mathrm{g} / \mathrm{kg}$, i.v.), but not methacholine (8 $\mu \mathrm{g} / \mathrm{kg}$, i.v.), produced a significant increase in gastric blood flow by means of either method. On the other hand. all secretagogues, in tested doses, significantly stimulated gastric acid secretion (Fig. 3)

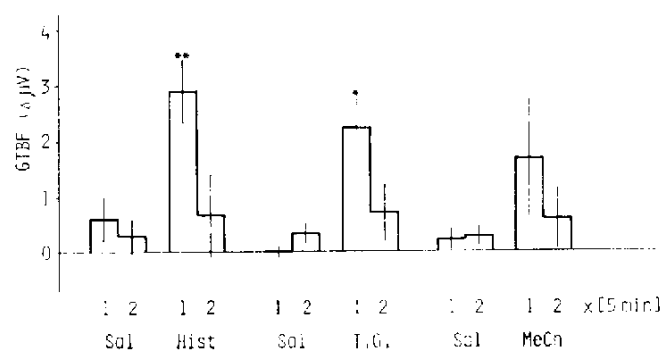

Fig. 2. Responses of GTBF to secretagogues by the cross thermocouple method. Sal; saline. Hist: histamine $(300 \mu \mathrm{g} / \mathrm{kg})$. T.G.; tetragastrin $(7.5 \mu \mathrm{g} / \mathrm{kg})$. MeCh; methacholine $(8 \mu \mathrm{g} / \mathrm{kg})$. All drugs were given i.v. The results of GTBF were estimated as the difference in the averaged potential level at each 5 -min interval from that observed before treatment, and expressed as the mean \pm S.E. of 9 experiments. ${ }^{*} \mathrm{P}<0.05,{ }^{*} \mathrm{P}<0.01$, when compared with the corresponding value of saline treatment.

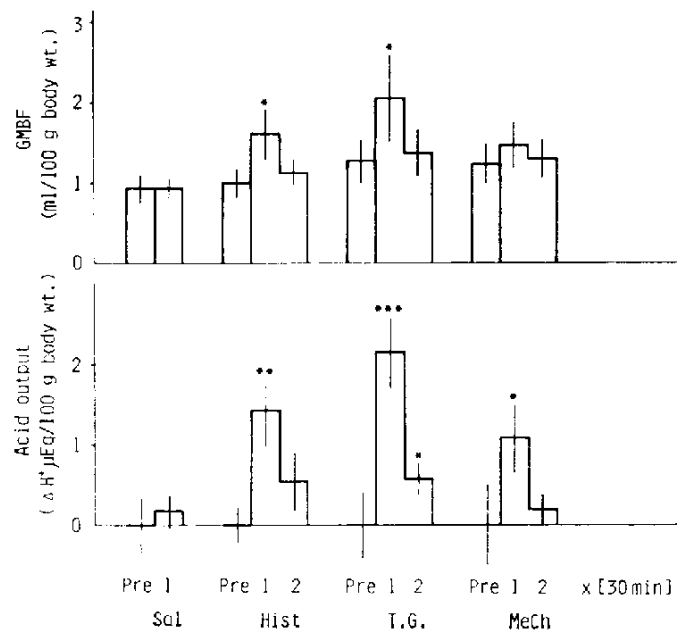

Fig. 3. Responses of GMBF and acid secretion to secretagogues by the aminopyrine clearance method. Pre; pretreatment. Other abbreviations or treatments are shown in Fig. 2. Results of GMBF and acid output were expressed as the mean $\pm S$.E. of 9 experiments at each 30 -min interval. The acid output was estimated as the difference in the amount of hydrogen ion from that observed during pretreatment. ${ }^{*} \mathrm{P}<0.05,{ }^{* *} \mathrm{P}<0.01,{ }^{* * *} \mathrm{P}<0.001$, when compared with the value of pretreatment. 
2. Responses of GTBF to vasoactive drugs with or without their antagonists, using the cross thermocouple method:

- Nor $0.25 \mu \mathrm{g} / \mathrm{rat}$
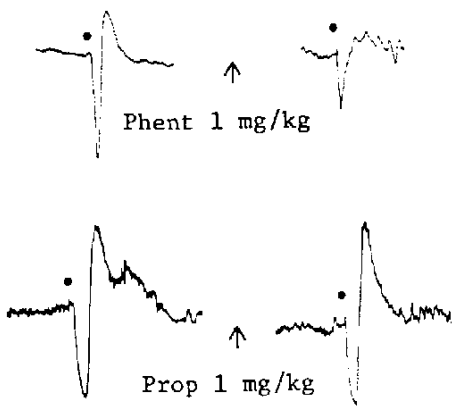

$\Delta$ Iso $0.25 \mu \mathrm{g} / \mathrm{rat}$

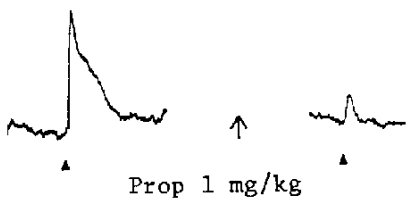

Typical patterns of GTBF in response to each vasoactive drug are shown in Figs. 4 and 5 . The antagonisms of responses of

- Epi $0.125 \mu \mathrm{g} / \mathrm{rat}$
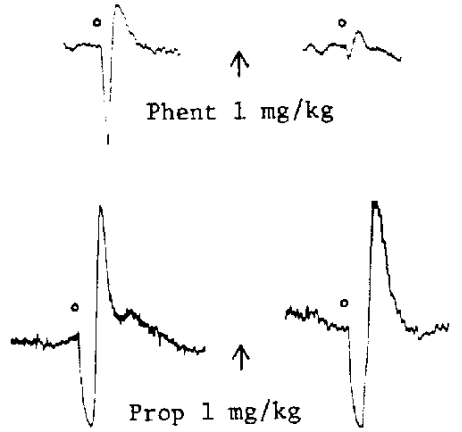

Fig. 4. Typical patterns of responses of GTBF to vasoactive drugs with or without their antagonists. Nor; norepinephrine. Epi; epinephrine. Iso: isoprenaline. Phent: phentolamine. Prop: propranolol. Agonists were given i.a., while antagonists were given i.v.

- Hist $5 \mu \mathrm{g} / \mathrm{rat}$

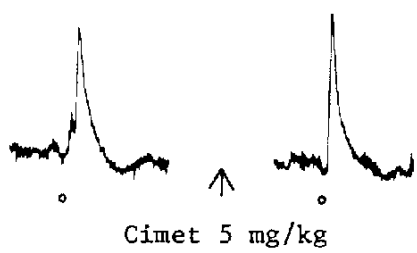

$\triangle \mathrm{ACh} 0.5 \mu \mathrm{g} / \mathrm{rat}$<smiles>CCCCCCC</smiles>

$$
\text { Atr } 0.1 \mathrm{mg} / \mathrm{kg}
$$

- Hist $10 \mu \mathrm{g} / \mathrm{rat}$

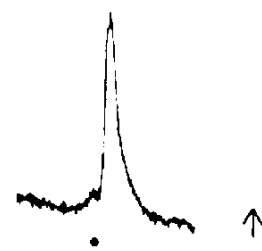

Diphen $10 \mathrm{mg} / \mathrm{kg}$

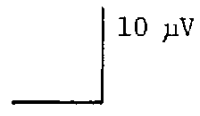

$10 \mathrm{~min}$

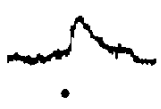

5-HT $1 \mu g /$ rat

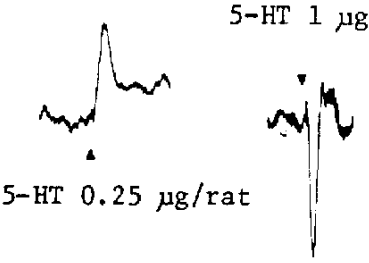

T.G. $1.5 \mu \mathrm{g} / \mathrm{rat}$

Fig. 5. Typical patterns of responses of GTBF to vasoactive drugs with or without their antagonists. ACh; acetylcholine. Hist; histamine. 5-HT; serotonin. T.G.; tetragastrin. Atr: atropine. Cimet; cimetidine. Diphen; diphenhydramine. Agonists were given i.a., while antagonists were given i.v. 
Table 1. Inhibition of the increasing or decreasing response of GTBF to vasoactive drugs by pretreatment with their antagonists

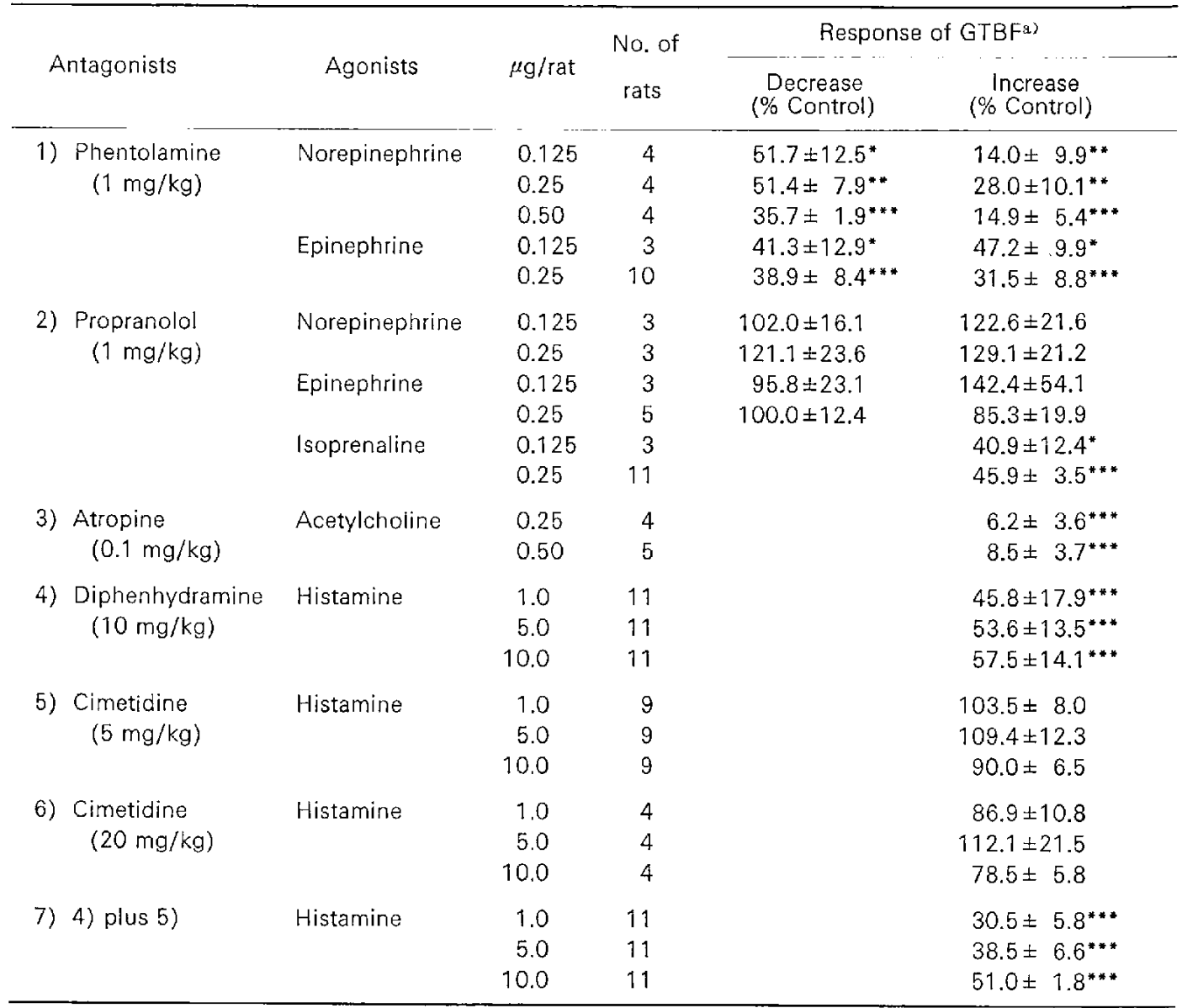

a) Responses of GTBF to an agonist were obtained before and after its antagonist(s). The extent of the latter responses was expressed as a percentage (the mean $\pm S$.E.) of the former potential level (control responses, i.e. $100 \%$ ). The results were analyzed statistically using a paired $t$ test. ${ }^{*} p<0.05,{ }^{*} p<0.01$. ** $p<0.001$, when compared with controls.

GTBF between vasoactive drugs and their antagonists are presented in Table 1.

Adrenergic agonists: Norepinephrine and epinephrine, which were tested in 0.125 and $0.50 \mu \mathrm{g} / \mathrm{rat}$, produced a biphasic response of GTBF; a decrease was initiated about $1 \mathrm{~min}$ after injection, followed by an increase about $2 \mathrm{~min}$ later. When the same dose was injected, epinephrine produced a more prominent action than did norepinephrine. Pretreatment with phentolamine, $1 \mathrm{mg} / \mathrm{kg}$. significantly antagonized this biphasic response to norepinephrine and epinephrine, while pretreatment with propranolol, $1 \mathrm{mg} / \mathrm{kg}$, produced no appreciable change. Isoprenaline, 0.125 and $0.25 \mathrm{\mu g} /$ rat, produced an increase in GTBF, and the peak of the increase was about 1 min after injection. This response was significantly blocked by propranolol, $1 \mathrm{mg} / \mathrm{kg}$.

Acetylcholine: Administration of acetylcholine, 0.25 and $0.50 \mu \mathrm{g} / \mathrm{rat}$, caused an increase in GTBF. The peak of the response occurred within $1 \mathrm{~min}$ after injection. Pretreat- 
ment with atropine, $0.1 \mathrm{mg} / \mathrm{kg}$, greatly inhibited this increase.

Histamine: Histamine, 1-10 $\mathrm{g} / \mathrm{rat}$, elicited an increase in GTBF. The peak of the increase was 1-2 min after injection. This was significantly antagonized by pretreatment with diphenhydramine, $10 \mathrm{mg} / \mathrm{kg}$, but not with cimetidine, 5 or $20 \mathrm{mg} / \mathrm{kg}$. A combination of these antagonists resulted in a somewhat greater inhibition as compared with the administration of diphenhydramine alone.

Serotonin: Patterns of responses to serotonin varied with the dosage. An increase in GTBF was elicited at $0.25 \mu \mathrm{g} / \mathrm{rat}$ of the drug. but was preceded by an apparent decrease when injected at $1.0 \mu \mathrm{g} / \mathrm{rat}$. With a higher dose, the peak of the decrease was about $1 \mathrm{~min}$ after injection and that of the increase about 2 min after injection.

Tetragastrin: Administration of tetragastrin. $1.5 \mu \mathrm{g} / \mathrm{rat}$, exerted an increase in GTBF, and the peak of the increase was about $1 \mathrm{~min}$ after injection.

Effect of i.a. administration of vasoactive drugs on blood pressure was estimated. Some of these drugs caused a moderate change in blood pressure at higher doses. but there was no case in which evaluation of their primary action on GTBF was made difficult by a modified blood pressure.

\section{DISCUSSION}

It is generally accepted that the aminopyrine clearance method is capable of assessing total mucosal blood flow in the stomach (2). In contrast with it, the cross thermocouple method measures regional blood flow at the area where a heat-sensitive element is implanted (7). Despite the thinness of the rat gastric mucosa, however, the implanted element was found to be placed mostly within the mucosal layer. Under such experimental situations, the experimental findings with the cross thermocouple method could be compared with those of the aminopyrine clearance technique regarding direction of responses of blood flow to three different secretagogues at dosages sufficient to stimulate gastric acid secretion. Moreover, it has been suggested that GMBF may occupy half the amount of total blood flow in rats (10). Thus, we considered that the gastric blood flow estimated by this method, i.e. GTBF, may well reflect the GMBF and that the cross thermocouple method is of practical value in evaluating the rat brief phasic changes.

There is apparently no documentation regarding continuously recorded rat gastric blood flow in response to vasoactive drugs. In studies using cats or dogs, drug responses are often variable, probably because of difference in dosage, route, or methodology $(11,12)$. The present experiments on drug responses, therefore, were designed so as to exhibit the primary action of drugs on gastric blood flow using an i.a. route of administration. Norepinephrine and epinephrine caused a biphasic response of blood flow. namely, a decrease followed by an increase in GTBF. The decreasing response, which occurs earlier, is assumed to be elicited by $\alpha$-adrenergic stimulation, because the response was blocked by phentolamine. On the other hand, mechanisms of eliciting the increase in GTBF seem to be complex. There is the possibility that $\beta$-adrenergic stimulation is responsible for the increase in GTBF, as was suggested from previous studies in dogs (12) and cats (13). However. our experiments with propranolol failed to support this possibility. Another possibility is that the increasing response originates from a decrease in GTBF itself, instead of being elicited by a direct action of norepinephrine or epinephrine. Such may be caused by the opening of the arterio-venous shunts which respond to the decrease (14), by autoregulatory escape mechanisms in the 
vessels which exhibit the decreasing response $(13,15,16)$, or by reactive hyperemia (17) possibly due to metabolic feedback which occurs during the decreasing response. Of these possible mechanisms, the presence of functional arterio-venous shunts in the rat stomach was not confirmed in the in vivo microscopical study of Guth and Smith (5). Accordingly, norepinephrine and epinephrine may elicit a decrease in GTBF through $\alpha$ adrenergic stimulation, leading to a secondary increase in GTBF through autoregulatory or metabolic mechanisms. On the other hand, only isoprenaline produced an increase in GTBF which was antagonized with propranolol. Thus, there probably are $\beta$ adrenergic receptors in the rat gastric vessels although the distribution is diffuse or the sensitivity is poor.

Histamine exerts an increase in gastric blood flow in association with stimulation of gastric secretion via histamine $\mathrm{H}-2$ receptors (18). However, it has been reported that the increasing response of gastric blood flow to histamine develops even in the presence of $\mathrm{H}-2$ receptor antagonists (1) and is reduced by pretreatment with $\mathrm{H}-1$ receptor antagonists (19). We also found that the increasing effect of histamine on GTBF was significantly inhibited with diphenhydramine but not with cimetidine although the antagonism was slightly augmented by a combination of these drugs. Thus, histamine probably increases gastric blood flow predominantly through stimulation of $\mathrm{H}-1$ receptors in the rat gastric vasculature. Different responses of gastric blood flow to cholinergic drugs have been reported (20,21). Likewise, vagal stimulation was reported to increase (22) or to decrease (23) in gastric blood flow. Our present results, including the antagonism between acetylcholine and atropine, favor the idea that acetylcholine exerts an increase in gastric blood flow through excitation of specific receptors.
Serotonin and gastrin are distributed mainly in the gastrointestinal tract. However, their primary actions on gastric blood flow of rats have never been elucidated. According to our results, serotonin causes an increase in GTBF but augments a decreasing response of GTBF with increasing dosage. Tetragastrin, a gastrin-like peptide, produced an increase in GTBF immediately after administration. Similar findings with pentagastrin have also been reported in the case of the canine stomach (19). The presence of the immediate response suggests that gastrin may increase gastric blood flow through its vasoactive actions other than mechanisms accompanying the stimulation of acid secretion.

It is essential to evaluate the primary responses of gastric blood flow to vasoactive drugs in order to understand the physiological or pharmacological actions on gastric functions. As the cross thermocouple method provides for a continuous recording of the gastric blood flow in rats, this method may be suitable for such evaluation.

Acknowledgement: We thank Smith Kline Fujisawa for the gift of cimetidine.

\section{REFERENCES}

1) Main, I.H. and Whittle, J.R.: A study of the vascular and acid-secretory responses of the rat gastric mucosa to histamine. J. Physiol. 257. $407-418$ (1976)

2) Lanciault, G. and Jacobson, E.D.: The gastrointestinal circulation. Gastroenterology $71,851-$ 873 (1976)

3) O'Brien, P. and Silen, W.: Effect of bile salts and aspirin on the gastric mucosal blood flow. Gastroenterology 64, 246-253 (1973)

4) Moody, F.G.: Role of mucosal blood flow in the pathogenesis of gastric ulcers. Pharmacology of gastrointestinal motility and secretion, Edited by Holton, P., Vol. 1, p. 339-360, Pergamon Press, Oxford (1973)

5) Guth, P.H. and Smith, E.: Neural control of gastric mucosal blood flow. Gastroenterology 69, 935-940 (1975)

6) Sato, N., Kamada, T., Shichiri, M., Kawano, S., 
Abe, H. and Hagihara, B.: Measurement of hemoperfusion and oxygen sufficiency in gastric mucosa in vivo. Evidence of mucosal hypoxia as the cause of hemorrhagic shockinduced gastric mucosal lesion in rats. Gastroenterology 76, 814-819 (1979)

7) Takahashi, l.: Studies on hepatic circulation by crossed double thermocouple. Folia pharmacol. japon. 60, 308-325 (1964) (Abs. in English)

8) Hagihara, Y.: Effects of ifenprodil on the regional blood flow in some organs of cats. Folia pharmacol. japon. 71, 709-725 (1975) (Abs. in English)

9) Jacobson, E.D., Linford, R.H. and Grossman, M.I.: Gastric secretion in relation to mucosal blood flow studied by a clearance technic. J. clin. Invest. 45, 1-13 (1966)

10) Shore, P.A., Brodie, B.B. and Hogben, C.A.M.: The gastric secretion of drugs: a $\mathrm{pH}$ partition hypothesis. J. Pharmacol. exp. Ther. 119, 361369 (1957)

11) Jacobson, E.D.: Effects of histamine, acetylcholine, and norepinephrine on gastric vascular resistance. Am. J. Physiol. 204, 1013-1017 (1963)

12) Zinner, M.J., Kerr, J.C. and Reynolds, D.G.: Adrenergic mechanisms in canine gastric circulation. Am. J. Physiol. 229, 977-982 (1975)

13) Ross, G.: Effects of epinephrine and norepinephrine on the mesenteric circulation of the cat. Am. J. Physiol. 212, 1037-1042 (1967)

14) Peters, R.M. and Womack, N.A.: Hemodynamics of gastric secretion. Ann. Surg. 148, 537-550 (1958)
15) Richardson, D.R. and Johnson, P.C.: Comparison of autoregulatory escape and autoregulation in the intestinal vascular bed. Am. J. Physiol. 217, 586-590 (1969)

16) Guth, P.H. and Smith, E.: Escape from vasoconstriction in the gastric microcirculation. Am. J. Physiol. 228, 1893-1895 (1975)

17) Folkow, B., Lundgren, 0 . and Wallentin, 1. : Studies on the relationship between flow resistance, capillary filtration coefficient and regional blood volume in the intestines of the cat. Acta physiol. scand. 57, 270-282 (1963)

18) Konturek, S.J., Tasler, J., Obtulowicz, W. and Rehfeld, J.F.: Effect of metiamide, a histamine $\mathrm{H}_{2}$-receptor antagonist, on mucosal blood flow and serum gastrin level. Gastroenterology 66, 982-986 (1974)

19) Gerkens, J.F., Flexner, C., Oates, J.A. and Shand, D.G.: Prostaglandin and histamine involvement in the gastric vasodilator action of pentagastrin. J. Pharmacol. exp. Ther. 201, 421-426 (1977)

20) Schnitzlein, H.N.: Regulation of blood flow through the stomach of the rat. Anat. Rec. 127, 735-753 (1957)

21) Meckeles, H., Frank, R., Kaye, E. and Rosenman, E.: Effect of acetylcholine on the blood flow through the stomach and legs of the rat. Am. J. Physiol. 114, 695-699 (1936)

22) Martinson, J.: The effect of graded vagal stimulation on gastric motility, secretion and blood flow in the cat. Acta physiol. scand. 65, 300-309 (1965)

23) Benjamin, H.B.: The neurovascular mechanism of the stomach and duodenum. Surgery Gynec. Obstet. 92, 314-320 (1951) 